\title{
ENERGY SPECTRA OF NEUTRONS AND GAMMA RAYS FROM SPONTANEOUS FISSION OF ${ }^{244} \mathrm{Cm}$
}

\author{
T. R. HEROLD
}
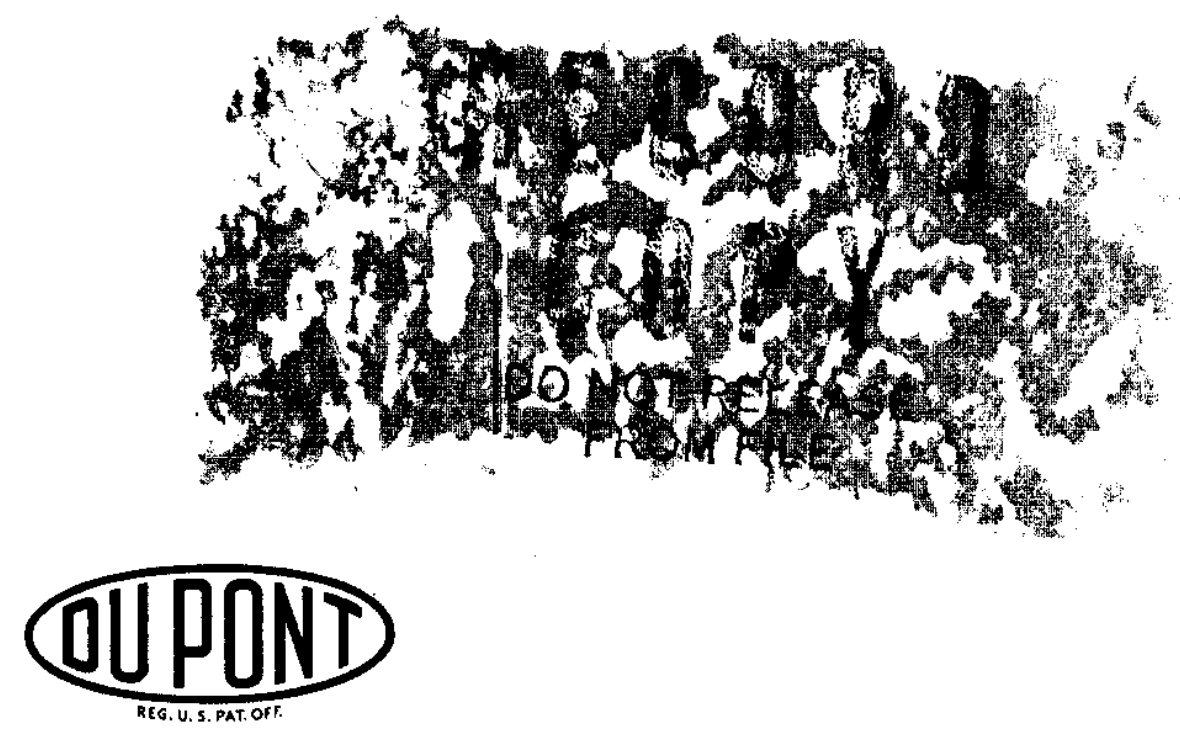

Savannah River Laboratory

Aiken, South Carolina 


\section{LEG A L NOTICE}

This report was prepared as an account of Government sponsored work. Neither the United States, nor the Commission, nor any person acting on behalf of the Commission:

A. Makes any warranty or representation, expressed or implied, with respect to the accuracy, completeness, or usefulness of the information contained in this report, or that the use of any information, apparatus, method, or process disclosed in this report may not infringe privately owned rights; or

B. Assumes any liabilities with respect to the use of, or for damages resulting from the use of any information, apparatus, method, or process disclosed in this report.

As used in the above, "person acting on behalf of the Commission" includes any employee or contractor of the Commission, or employee of such contractor, to the extent that such employee or contractor of the Commission, or employee of such contractor prepares, disseminates, or provides access to, any information pursuant to his employment or contract with the Commission, or his employment with such contractor.

Printed in USA. Price $\$ 2.00$

Available from the Clearinghouse for Federal Scientific and Technical Information, National Bureau of Standards,

U. S. Department of Commerce, Springfield, Virginia 


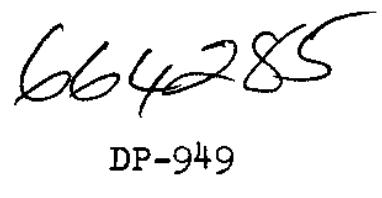

(TID-4500, 45th Ed.)

\title{
ENERGY SPECTRA OF NEUTRONS AND GAMMA RAYS FROM SPONTANEOUS FISSION OF ${ }^{244} \mathrm{~cm}$
}

\author{
by \\ T. Richard Herold \\ Approved by \\ D. E. Waters, Manager \\ Laboratory Operations and Services Division \\ July 1965
}

E. 1. DU PONT DE NEMOURS \& COMPANY SAVANNAH RIVER LABORATORY

AIKEN, SOUTH CAROLINA

CONTRACT AT(07.2).1 WITH THE

UNITED STATES ATOMIC ENERGY COMMISSION 


\begin{abstract}
The energy spectrum of the neutrons from the spontaneous fission of $244 \mathrm{Cm}$ was measured from 0.5 to $6 \mathrm{Mev}$ with a solid state ${ }^{3} \mathrm{He}$ spectrometer. The spectrum shows a maximum at about $0.75 \mathrm{Mev}$ and decreases exponentially above $2 \mathrm{Mev}$.

The energy spectrum of the gamma rays that were emitted within 180 nanoseconds of the spontaneous f1ssion neutrons was measured from 0.1 to $2.5 \mathrm{Mev}$ w1th a gamma ray spectrometer that included the ${ }^{3} \mathrm{He}$ spectrometer in a colncidence circuit. The gamma ray spectrum shows a dual-peak maximum at about 200 kev and decreases exponentlally above $800 \mathrm{kev}$.

Both measured spectra are similar to the corresponding spectra from the spontaneous fission of ${ }^{252} \mathrm{Cf}$.

The measurements were made with a purlfied sample of 95.5 wt $\%{ }^{244} \mathrm{Cm}$ that was produced in a Savannah R1ver reactor.
\end{abstract}




\section{CONTENTS}

\section{Page}

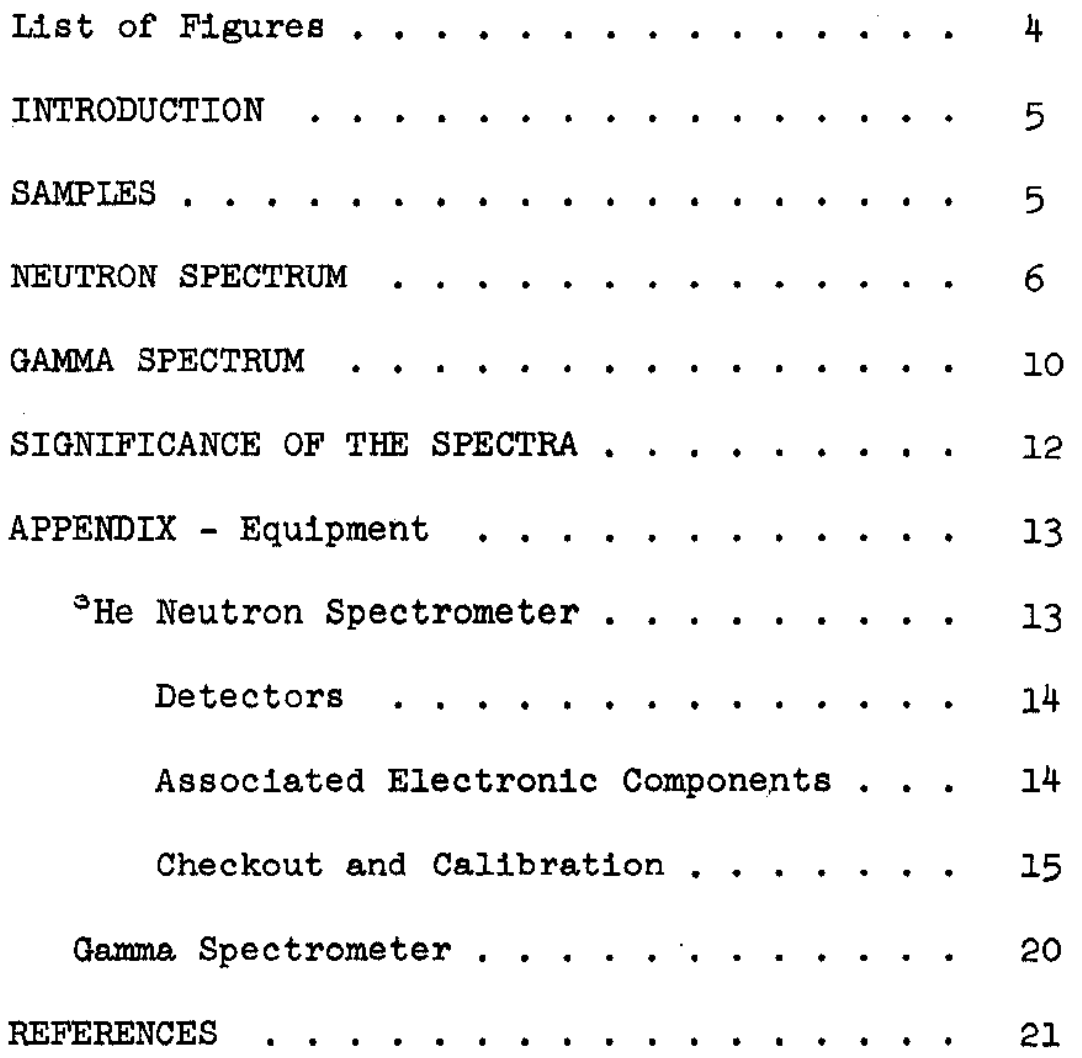




\section{LIST OF FIGURES}

Figure

$\underline{\text { Page }}$

1 Spontaneous F1ssion Neutron Spectrum of ${ }^{244} \mathrm{Cm}$. . . . . 7

2 Neutron Cross Section for the ${ }^{3} \mathrm{He}(\mathrm{n}, \mathrm{p})$ Reaction..... 8

3 Fission Neutron Spectra . . . . . . . . . . . 9

4 Gamma Spectra of ${ }^{244} \mathrm{Cm}$ and ${ }^{252} \mathrm{Cf}$. . . . . . . . 10

5 Corrected Gamma Spectra of ${ }^{244} \mathrm{Cm}$ and ${ }^{252} \mathrm{Cf}$. . . . . . . II

$6 \quad \operatorname{NaI}(\mathrm{TI})$ Detector Efficiency versus Gamma Energy . . . . 12

7 Sectional View of the ${ }^{3} \mathrm{He}$ Neutron Spectrometer . . . . 13

8 Instruments Used to Measure Neutron Spectra. . . . . 15

9 Detector Response to Thermal Neutrons......... . 16

10 Calibration Data from Neutron Generator . . . . . . . 17

1 Electronic System Response to Pulse Generator Input . . . 18

12 Effect of Electronic Gain on Thermal Peak Position . . . 19

13 Instruments Used to Measure Gamma Spectra. . . . . . . 20 


\title{
ENERGY SPECTRA OF NEUTRONS AND GAMMA RAYS FROM SPONTANEOUS FISSION OF ${ }^{244} \mathrm{Cm}$
}

\author{
INTRODUCTION
}

Curium-244 is an alpha emitter with a half-life of about 19 years and with a power density about five times that of $238 \mathrm{Pu}$. The high specific power and relatively long half-life of ${ }^{244} \mathrm{Cm}$ makes it especially attractive as a long-term nuclear heat source.

A pllot production program for ${ }^{244} \mathrm{Cm}$ is under way at the Savannah River Plant $(1)$ to demonstrate that the isotope can be produced in relatively large quantities at reasonable cost. The program will also provide three kilograms of ${ }^{244} \mathrm{Cm}$ for the development and demonstration of nuclear electric power generators fueled with this isotope.

In addition to emitting alpha particles, $244 \mathrm{Cm}$ fissions spontaneous $1 \mathrm{y}$ and therefore requires protective shielding to attenuate the fast neutrons and hard gamma rays from the fission process. The present work was undertaken to measure the energy spectra of neutrons and gamma rays from the spontaneous fission of ${ }^{244} \mathrm{Cm}$ in order to provide an empirical basis for shlelding calculations. The work is of general scientific interest because these spectra have not been previously reported in the literature. Some preliminary work on the neutron spectrum was done by the author at the Savannah River Laboratory in August 1964 for inclusion in a report on the radiation characteristics of $244 \mathrm{~cm}$. (2)

The neutron spectrum was measured with a solid state ${ }^{3} \mathrm{He}$ neutron spectrometer that records nuclear events in ${ }^{3} \mathrm{He}$ gas. This technique for determining neutron spectra is new and provides a significant improvement over the time-of-flight techniques and the proton-recoli-inemulsion techniques previously used. The gamma spectrum was measured with a gamma ray spectrometer that included the ${ }^{3} \mathrm{He}$ neutron spectrometer in a $(\gamma, n)$ coincidence clrcuit.

\section{SAMPLES}

The ${ }^{244} \mathrm{Cm}$ sample was prepared by dissolving a 7.1-mg sample of purified curium ${ }^{(3)}$ in $2.2 \mathrm{ml}$ of $\mathrm{HNO}_{3}$ (IM) and placing the resulting solution in a small glass pipet. Mass spectrometric analyses of the sample showed that it contained 95.5 wt $\%{ }^{244} \mathrm{Cm}, 2.7$ wt $\%{ }^{248} \mathrm{Cm}$, 1.6 wt $\%{ }^{245} \mathrm{Cm}, 0.12$ wt $\%{ }^{242} \mathrm{Cm}, 0.04$ wt $\%{ }^{247} \mathrm{~cm}, 0.04$ wt $\%{ }^{248} \mathrm{~cm}$, $0.03 \mathrm{wt} \%{ }^{243} \mathrm{Cm}$, and trace amounts of ${ }^{243} \mathrm{Am}$ and ${ }^{252} \mathrm{Cf}$. Most of the neutrons emitted from the sample derive from the spontaneous fission of 
$244 \mathrm{Cm}$, with minor contributions from the spontaneous fission of ${ }^{242} \mathrm{Cm}$, ${ }^{246} \mathrm{Cm}$, and ${ }^{252} \mathrm{Cf}$. A second minor'source of neutrons 1 s from the reaction of alpha particles with light elements, for example, the $(\alpha, n)$ reaction with oxygen in $\mathrm{CmO}_{2}$.

About 1.2 nanograms of ${ }^{252} \mathrm{Cf}$ was obtalned from the curium purification. The ${ }^{252} \mathrm{Cf}$ sample was radiochemically free of other alpha- and gamma-emitting nuclides. The fission gamma spectrum of this sample was measured for comparison with the simllar $244 \mathrm{~cm}$ spectrum measured and with the ${ }^{252} \mathrm{Cf}$ spectrum recently reported by another laboratory. (12)

\section{NEUTRON SPECTRUM}

The spectrum of spontaneous f1ssion neutrons from ${ }^{244} \mathrm{Cm}$ was measured with the ${ }^{3} \mathrm{He}$ neutron spectrometer and associated electronic equipment described in the Appendix, which also contains details of the instrument checkout and calibration.

The ${ }^{244} \mathrm{Cm}$ sample was taped tightly to the ${ }^{3} \mathrm{He}$ spectrometer, which was covered with 0.030 inch of cadmium to shleld the detectors from thermal neutrons. The spectrometer and sample were then suspended from the laboratory celling so that the spectrometer-sample assembly was at least $5 \mathrm{ft}$ away from any large scattering object.

The neutron spectrum of ${ }^{244} \mathrm{Cm}$ was obtained in energy increments of approximately 0.5 to $1.1 \mathrm{Mev}, 1.0$ to $2.2 \mathrm{Mev}, 2.0$ to $3.5 \mathrm{Mev}$, and 3.0 to $6.0 \mathrm{Mev}$, with the biased amplifier technique described in the Appendix. The date were normallzed to produce the spectrum shown in Figure 1. The spectrum shows a maximum at about $0.75 \mathrm{Mev}$ and decreases exponentlally above $2 \mathrm{Mev}$. This spectrum has been corrected for background. Background counts in each energy increment were obtained by separating the spectrometer and sample by 6 inches to reduce the direct count rate from the sample by about 99\%. Signal-minus-background counts were corrected for the variation in the ${ }^{3} \mathrm{He}(n, p)$ cross section with neutron energy, with the curve shown in Figure 2, which represents the average of data reported by several investigators. (4-7)

Figure 3 shows the ${ }^{244} \mathrm{Cm}$ spectrum along with the reported experimental spectra of $233 \mathrm{U},(8) 235 \mathrm{U},(\theta) 239 \mathrm{Pu},(10)$ and $252 \mathrm{Cf}(11)$ for comparison. The normalization of the curves shown in Figure 3 was chosen for clear representation and is otherwise arbitrary. 


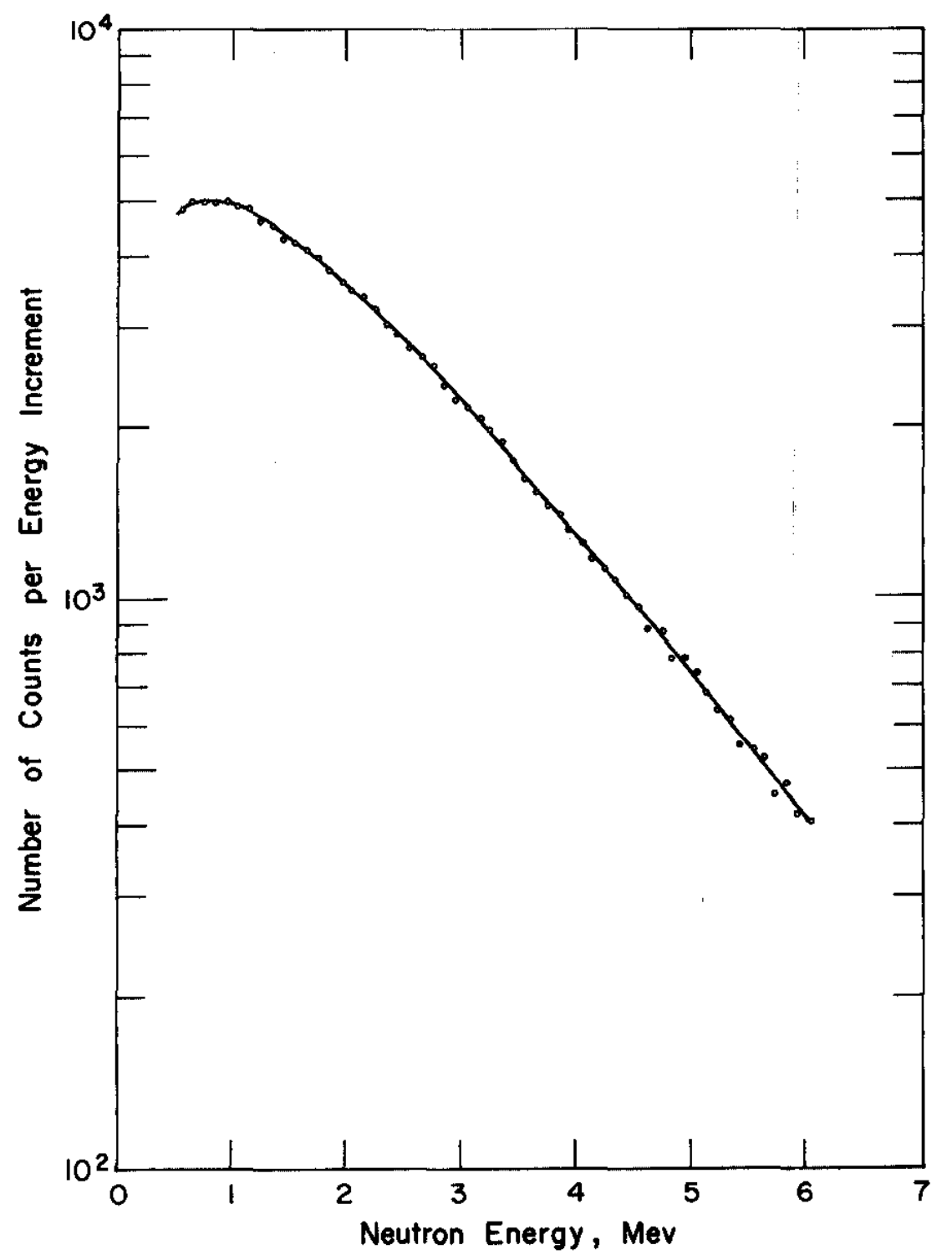

FIG. 1 SPONTANEOUS FISSION NEUTRON SPECTRUM OF ${ }^{244} \mathrm{Cm}$ 


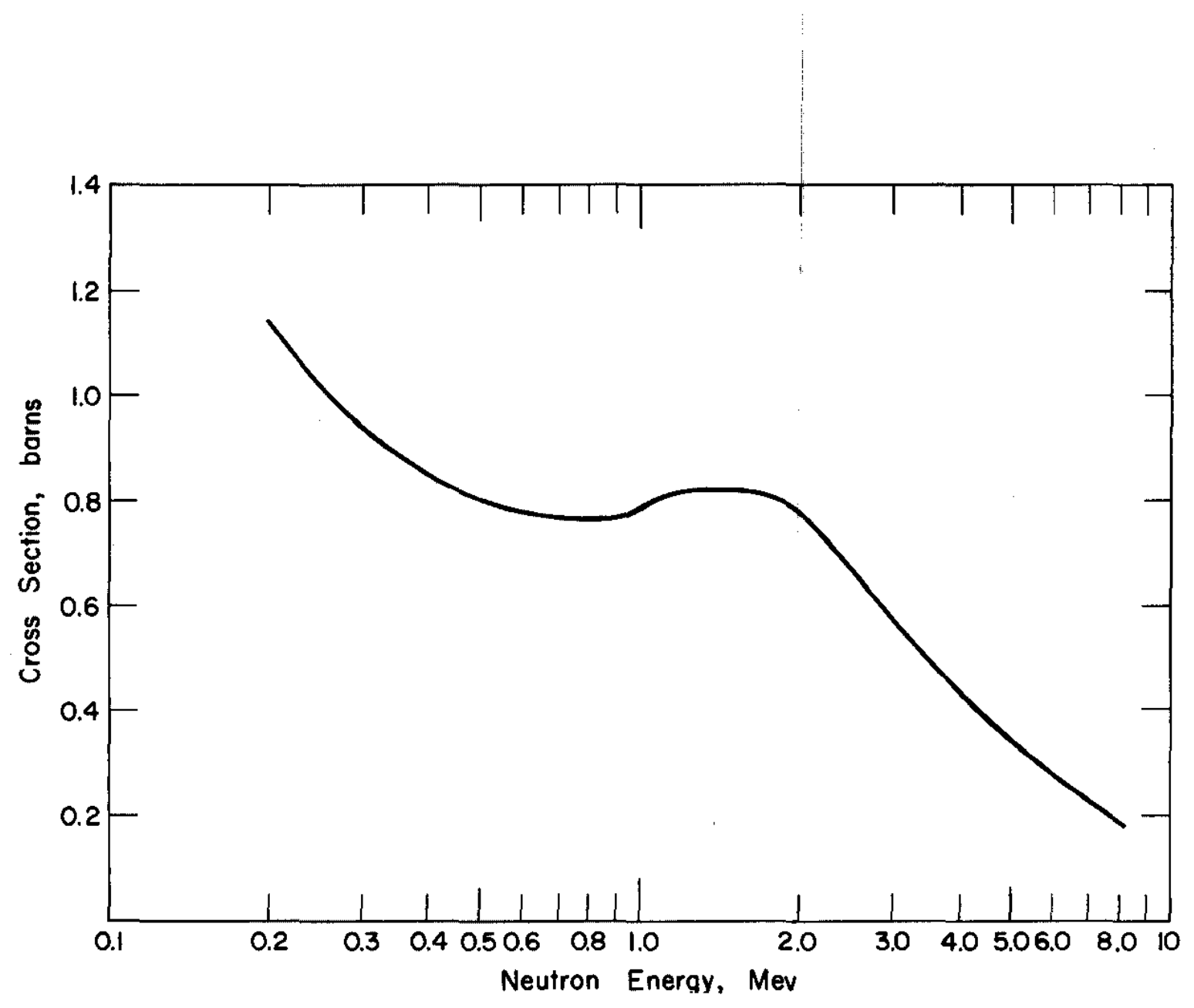

FIG. 2 NEUTRON CROSS SECTION FOR THE ${ }^{3} \mathrm{He}(n, p)$ REACTION 


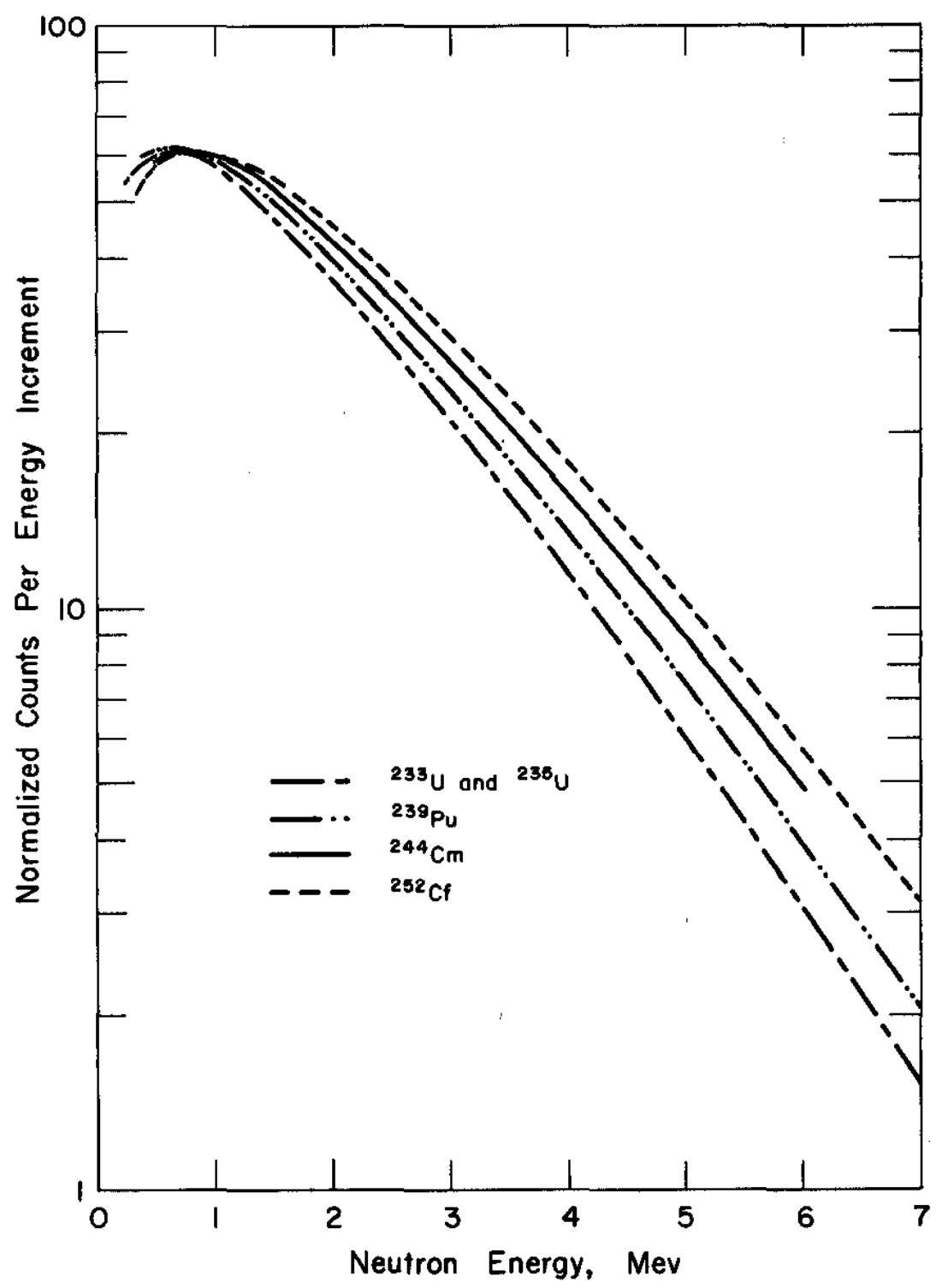

FIG. 3 FISSION NEUTRON SPECTRA 


\section{GAMMA SPECTRUM}

The ${ }^{3} \mathrm{He}$ neutron spectrometer and a conventional NaI(Tl) gamma spectrometer were arranged in $a(\gamma, n)$ coincidence circuit to record the energy spectrum of gamma rays that were emitted within 180 nanoseconds of spontaneous fission neutrons. This equipment is described in the Append1x.

The ${ }^{244} \mathrm{Cm}$ sample was taped snugly to the cadmium-covered ${ }^{3} \mathrm{He}$ neutron spectrometer as it was for the neutron spectrum measurements. The sample also rested on top of the 3-1nch NaI(TI) crystal of the scintiliation detector.

Figure 4 shows the measured gamma energy spectrum of ${ }^{244} \mathrm{Cm}$ and also shows the ${ }^{252} \mathrm{Cf}$ spectrum measured by the same method. Both spectra

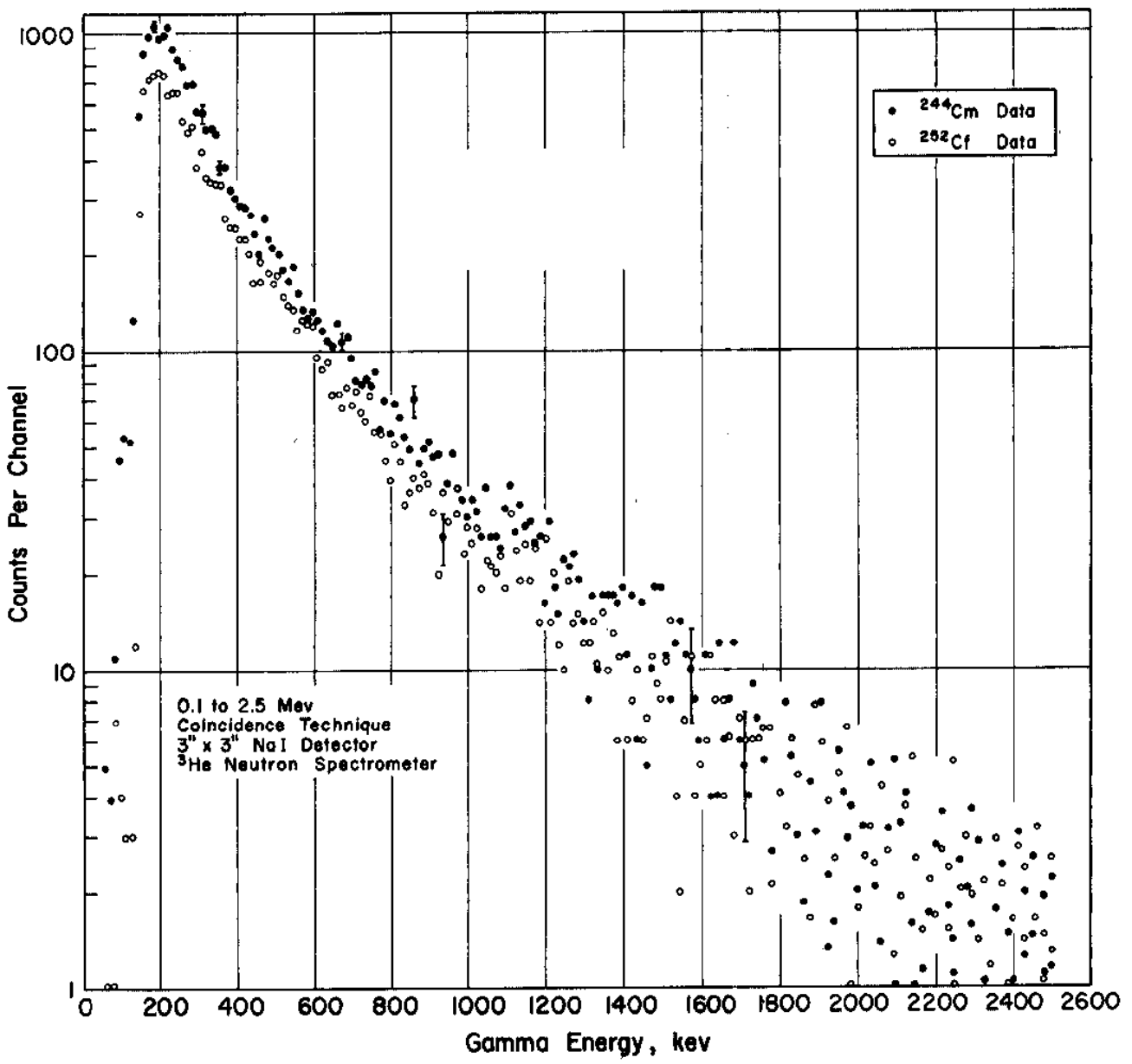

FIG. 4 GAMMA SPECTRA OF ${ }^{244} \mathrm{Cm}$ AND ${ }^{252} \mathrm{CF}$ 
exhiblt a dual-peak maximum at about $200 \mathrm{kev}$ and decrease exponentially above $800 \mathrm{kev}$. In these complex spectra, there 1s some evidence of peaks which would possibly become statistically significant if more counts per energy interval were accumulated.

Flgure 5 shows the ${ }^{244} \mathrm{Cm}$ and ${ }^{252} \mathrm{Cf}$ spectra that resulted from correcting the raw data of Flgure 4 for detector efficlency and fitting them to a smooth curve. Figure 6, a plot of NaI(TI) detector efficlency versus gamma energy, was used to make the corrections.

Figure 5 also shows for comparison the total prompt gamma energy spectrum from ${ }^{252} \mathrm{Cf}$ that was recently measured by another technique. (12)

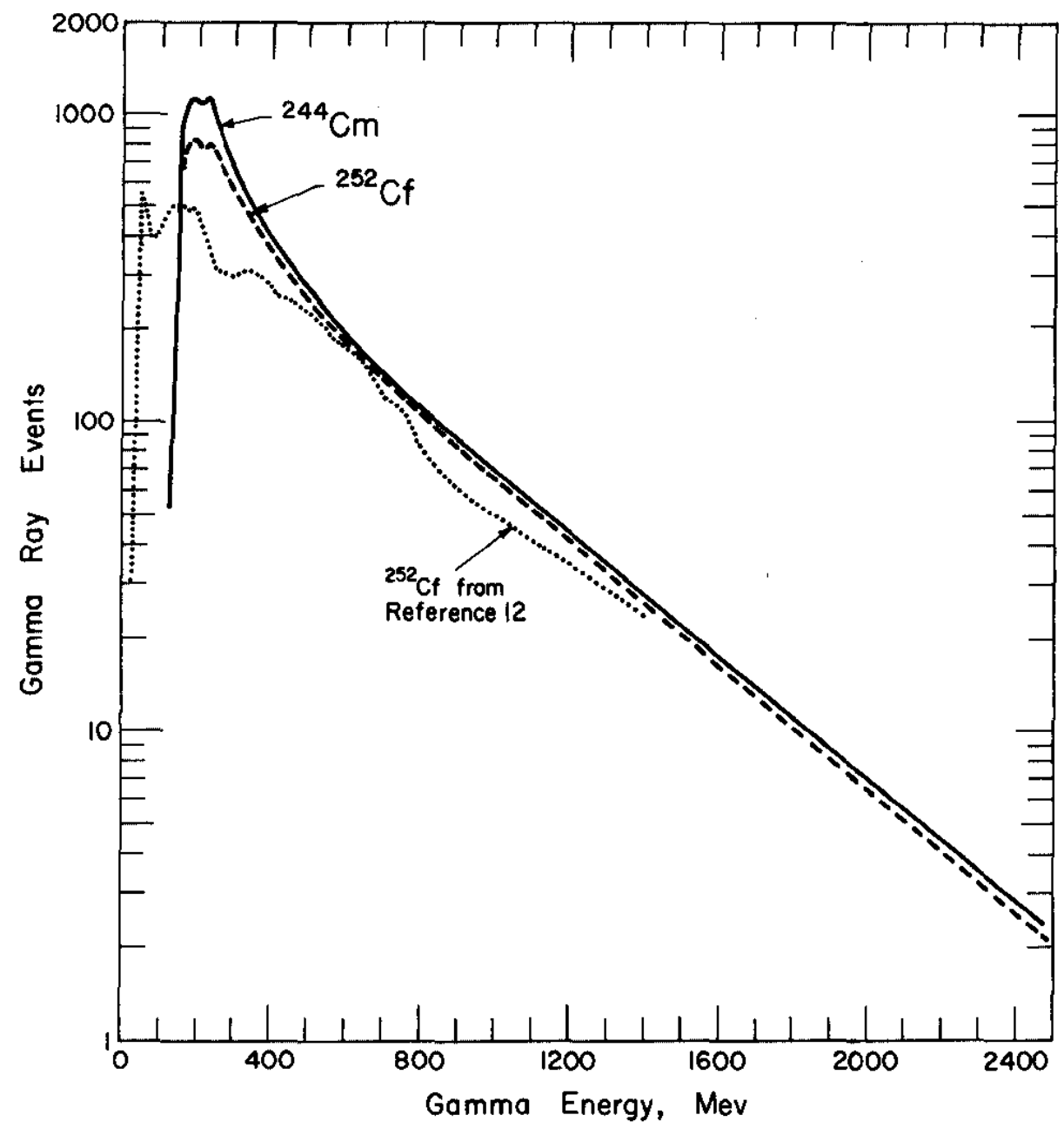

FIG. 5 CORRECTED GAMMA SPECTRA OF ${ }^{244} \mathrm{Cm}$ AND ${ }^{252} \mathrm{Cf}$ 


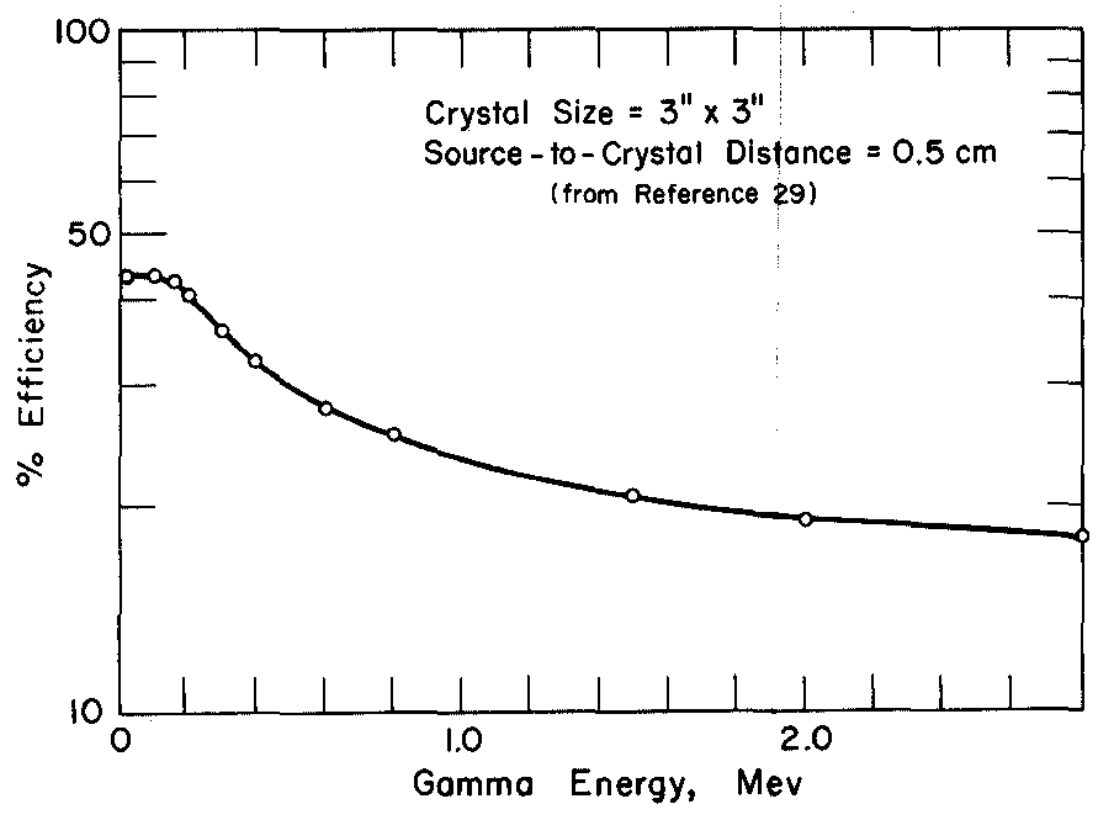

FIG. 6 NaI(TI) DETECTOR EFFICIENCY VERSUS GAMMA ENERGY

\section{SIGNIFICANCE OF THE SPECTRA}

All experimental energy distributions for fission neutrons are similar whether the neutrons derive from induced flssion as in the case of ${ }^{23{ }^{3} \mathrm{U},}{ }^{233} \mathrm{U}$, or ${ }^{239} \mathrm{Pu}$, or from spontaneous fission as in the case of $244 \mathrm{Cm}$ or ${ }^{252} \mathrm{Cf}$. In all cases a Maxwellian distribution is obtalned as predicted by Weisskopf's evaporation theory. (13) This theory is a thermodynamic analogy that compares the energy stored in a compound nucleus with the heat energy of a solid or a liquid. Frenkel(14) first emphasized that the subsequent explusion of particles from the compound nucleus was analogous to an evaporation process from a solid or a liquid. All predictions of fission neutron spectra assume that the neutrons are emitted from moving fission fragments. (15) This assumption is in agreement with all reported experimental data, both as to the general shape of the spectra and as to the directional correlation of neutrons and fragments. (Io)

Predictions of the fission-assoclated gamma ray spectra have not been reported on the basis of theorles of flssion. Therefore, experiments provide the only access to these spectra. The general assumption Is that the observed continuous spectrum is produced by the decay of a statistical ensemble of many levels. $(17)$ 


\section{APPENDIX}

\section{EQUIPMENT}

The development of semiconductor charged-part1cle detectors $(18,10)$ has enabled the development of fast neutron spectrometers that provide 100- to 150-kev energy resolution over a wide range of neutron energies. Several spectrometers have been reported that detect neutrons by such exothermic secondary reactions as ${ }^{3} \mathrm{He}(n, p),{ }^{6} \mathrm{LI}(n, \alpha),{ }^{10} \mathrm{~B}(n, \alpha)$, and ${ }^{1} \mathrm{H}(n, p) \cdot(20-24)$ Such spectrometers can be used to measure neutron spectra rapidly and rather simply. $(25,26)$

${ }^{3}$ He NEUTRON SPECTROMETER

A ${ }^{3} \mathrm{He}$ neutron spectrometer was used to measure the spectrum of the spontaneous fission neutrons from ${ }^{244} \mathrm{Cm}$. Figure 7 is a sectional view of the spectrometer, which consists basically of two closely spaced silicon surface-barrier detectors w1th h1gh-pressure ${ }^{3} \mathrm{He}$ gas between and surrounding the detectors. The assembly is sealed in an aluminum can about $1-1 / 2$ inches 1 d dameter and $1-1 / 2$ 1nches long. The can w1Il w1thstand pressures up to 20 atmospheres.

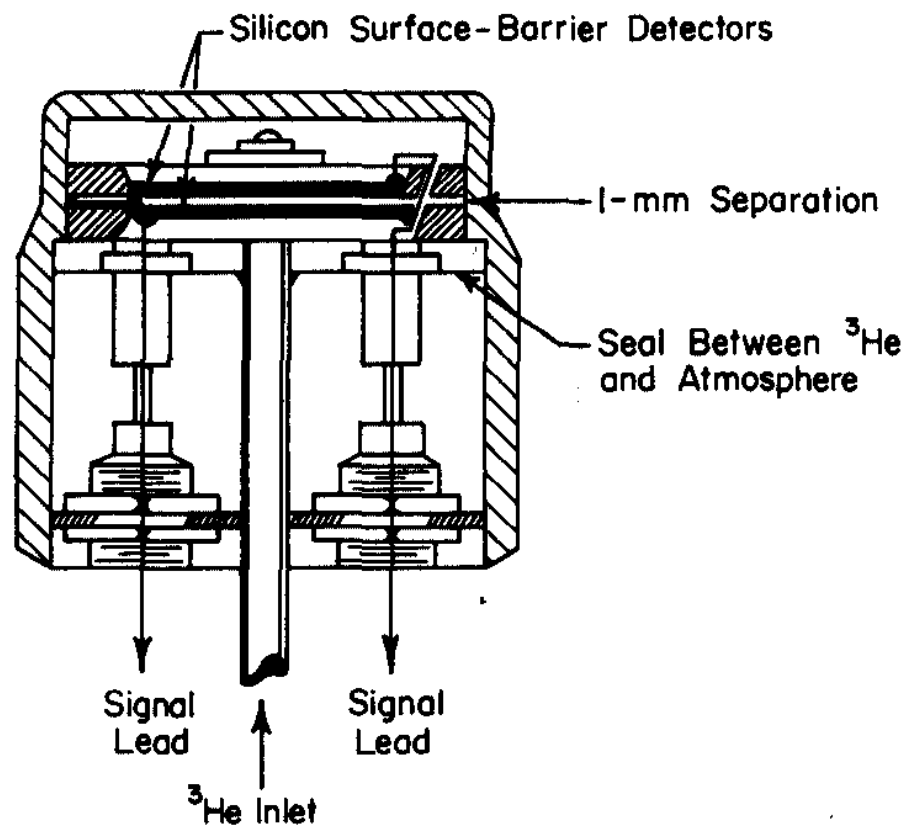

FIG. 7 SECTIONAL VIEW OF THE ${ }^{3}$ He NEUTRON SPECTROMETER 
Fast neutrons incident on the assembly cause ${ }^{3} \mathrm{He}(n, p) \mathrm{T}$ events in the ${ }^{3} \mathrm{He}$ gas, releasing a total energy to the proton and triton equal to the neutron energy plus the reaction Q-value $(0.76 \mathrm{Mev})$. Some of the protons and tritons enter the s1licon detectors and create free electron-hole pairs at the rate of $3.4 \mathrm{ev} /$ electron-hole pair. The detector response is linear with energy over a wide range, provided the sensitive depth of the detector exceeds the range of the particle, and the electric field in the sensitive region is large enough to separate the charged palrs before they recombine. The total energy of the proton and triton from a given reaction is obtained by summing the output pulses from the two detectors. Thus, the amplitude of the summed pulse is proportional to the energy of the incident neutron. The $Q$-value of the reaction provides a bullt-in blas against low-energy background events.

\section{Detectors}

The two silicon surface-barrier detectors in the ${ }^{3} \mathrm{He}$ neutron spectrometer were made of nominal $5000-0 \mathrm{hm}-\mathrm{cm}$ slilicon and were carefully matched by the vendor. Each detector had an active area of $280 \mathrm{~mm}^{2}$, a FWHM nolse width of $21 \mathrm{kev}$, a reverse current of $0.2 \mathrm{microampere,} \mathrm{and}$ a depletion depth of $250 \mathrm{mlcrons}$ at 50 -volts operating blas. The depletion depth was sufflclent to absorb totally elther 20-Mev tritons or $5.5-\mathrm{Mev}$ protons.

\section{Assoclated Electronic Components}

Figure 8 shows the instruments used to test the spectrometer and to measure the neutron spectrum.

Charge-sensit1ve preamplifiers must be used with semiconductor detectors because these detectors do not have the internal multiplication of signal that Geiger counters or proportional counters have. Only the electric charge created along the path of the charged particle in the depleted silicon is avaliable as an input signal to the electronic system. Th1s circumstance imposes a severe low-nolse requirement on the input stage of the preamplifier to obtain a satisfactory signal-tonolse ratio and to minimize the resolution spread due to electronic system noise. The preamplifiers shown in Figure 8 were satisfactory in this regard and converted input charge bursts from nuclear events into voltage pulses, which were fed to the respectlve amplifiers.

The output pulses from the amplifiers were added algebraically in the passive sum network and fed to the biased amplifier. The biased amplifier was necessary to obtain a sufficient number of analyzer channels over a spectrum peak or other region of interest. By this 


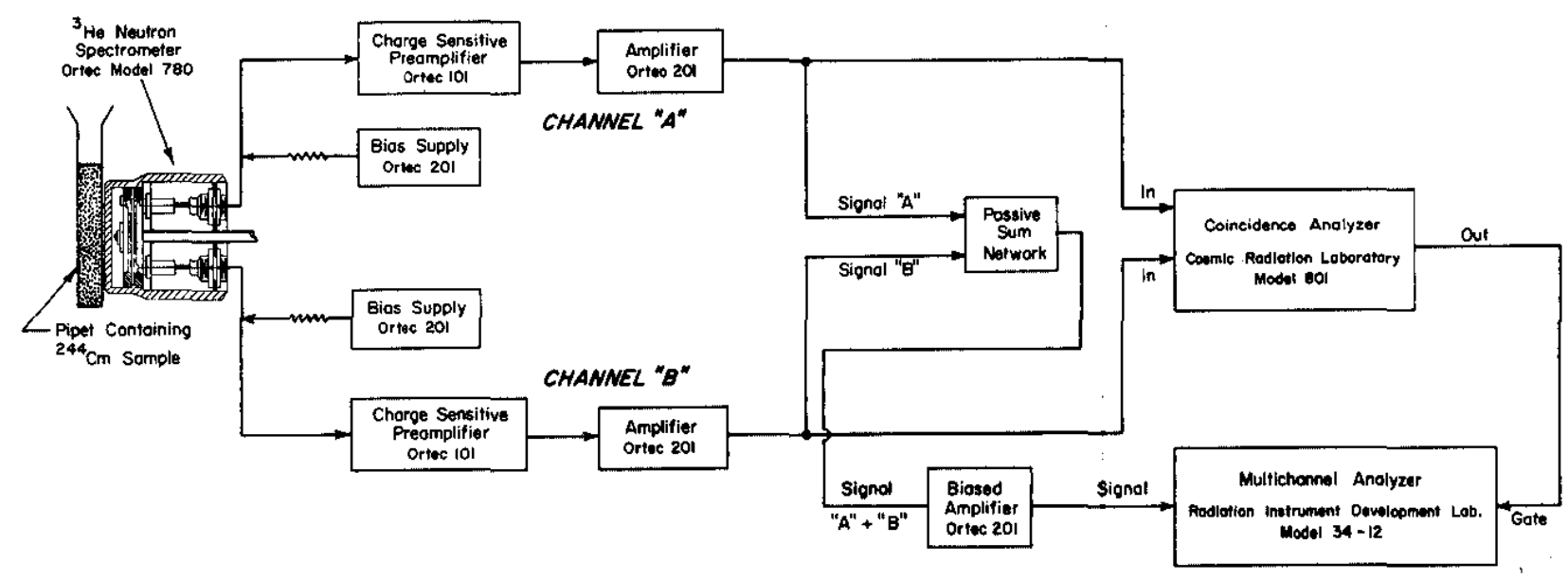

FIG. B INSTRUMENTS USED TO MEASURE NEUTRON SPECTRA

means all of the spectrum that was below a chosen energy was suppressed, and the remaining region was expanded as desired with blased amplifier gain before pulse height analysis.

The output pulses from the blased amplifier were fed to the input of the multichannel analyzer. The multichannel analyzer recorded only those nuclear events in which the triton from a given reaction was absorbed in one detector while the corresponding proton was absorbed in the opposite detector. To eliminate signals from other nuclear events the colncidence analyzer provided an output signal only when the input signals from the two detectors occurred within 180 nanoseconds. The output signal from the two colncident input slgnals was used to open the gate of the multichannel analyzer so as to record the energy of the neutron that particlpated in the two-way coincidence.

\section{Checkout and Calibration}

The spectrometer, which was fllled with air when recelved from the vendor, was initialiy evacuated to 5 microns and checked for its response to neutrons from a bare Pu-Be source ( 1 curle) and to gamma radiation from millicurle sources of ${ }^{137} \mathrm{Cs}$ and ${ }^{60} \mathrm{Co}$. A large number of low-energy counts were observed with the neutron source, and a smaller number with the gamma sources. Several counts were observed with the neutron source in the higher energy range and were probably due to neutron-induced reactions in the silicon. (27) All of the highenergy counts and most of the low-energy counts were eliminated with the colncldence analyzer. 
The spectrometer was then filled to a pressure of 75 psi with ${ }^{3} \mathrm{He}$ from the tank supplied by the vendor and was exposed to thermalized neutrons from a paraffin-moderated, Pu-Be source. After the detectors were tested individually without coincidence to determine that they had the same energy response, they were tested together with coincidence to determine the energy resolution of the summed thermal peak. The data obtained are shown in Figure 9.

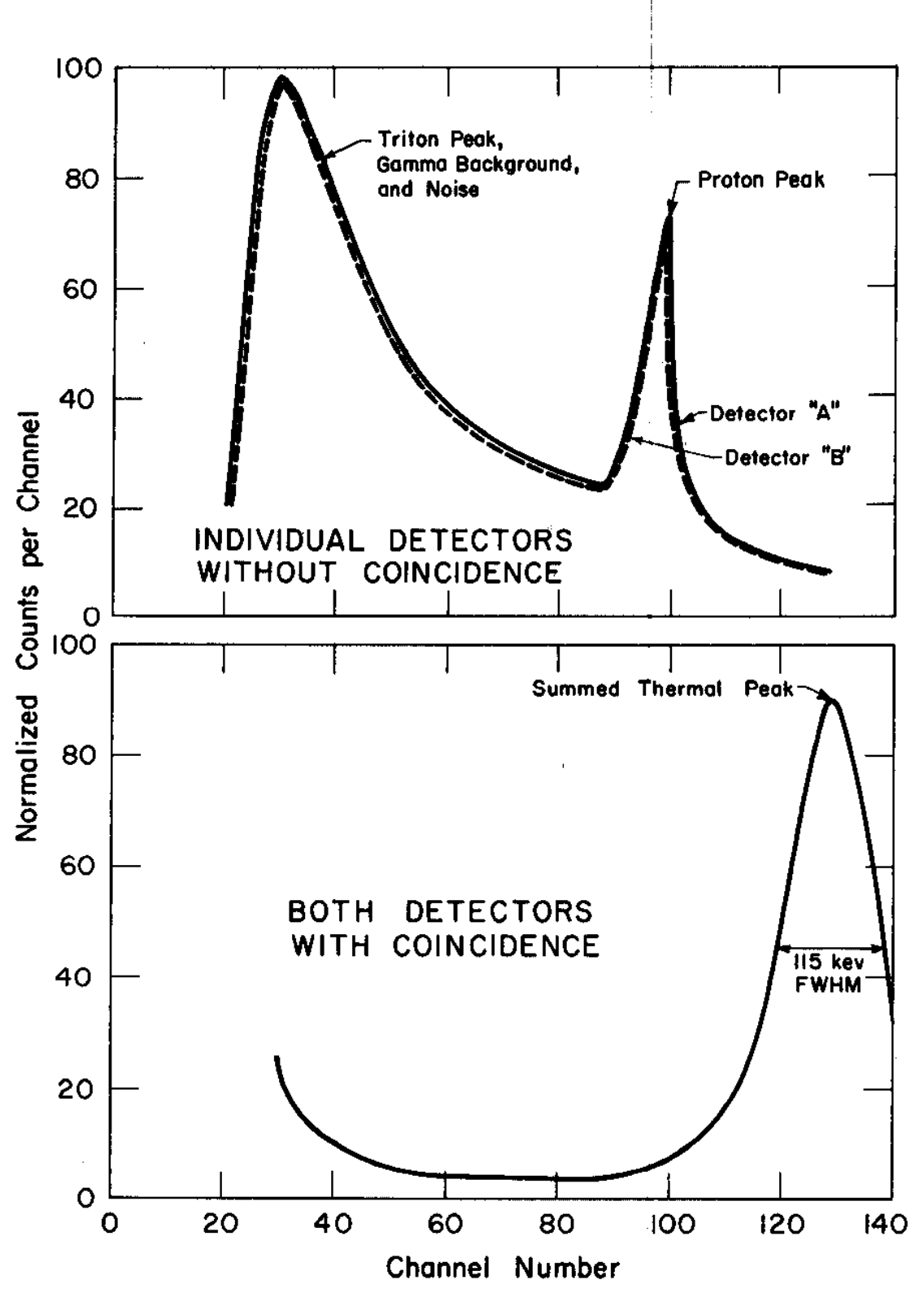

FIG. 9 DETECTOR RESPONSE TO THERMAL NEUTRONS 
Primary calibration of the system was accomplished by detecting neutrons produced by the $d(d, n)^{3}$ He reaction in a neutron generator. The $d(d, n)^{3}$ He reaction was obtained by spraying a defocused deuteron beam over a relatively large area of stainless steel target and then bombarding a small area of the target with a focused deuteron beam. The neutron energy varied as a function of angle from the target, being $2.80 \mathrm{Mev}$ at $0^{\circ}$ and $2.20 \mathrm{Mev}$ at $135^{\circ}$. (28) These two energy groups are resolved by the detector and are shown in Figure 10. The larger FWHM value for the $0^{\circ}$ energy group was probably caused by the presence of cooling water between the target and the ${ }^{3} \mathrm{He}$ spectrometer at the $0^{\circ}$ position.



FIG. 10 CALIBRATION DATA FROM NEUTRON GENERATOR 
The overall linearity of the electronic system was determined with a precision pulse generator that sent identical pulses into the inputs of both preamplifiers. The gain of each preamplifier-amplifier channel was first adjusted so that the amplitudes of the pulses going from each channel 1nto the sum network were equal. The amplitude of the output pulses from the pulse generator was then varled to produce the response curve shown at the top of Figure 11. Th1s curve was taken with the amplifier gain control in the $x 4$ position. Figure 11 also shows the effect of changing the amplifier gain control to elther the $x 2$ or $x I$ position, with the same pulse generator settings that were used with

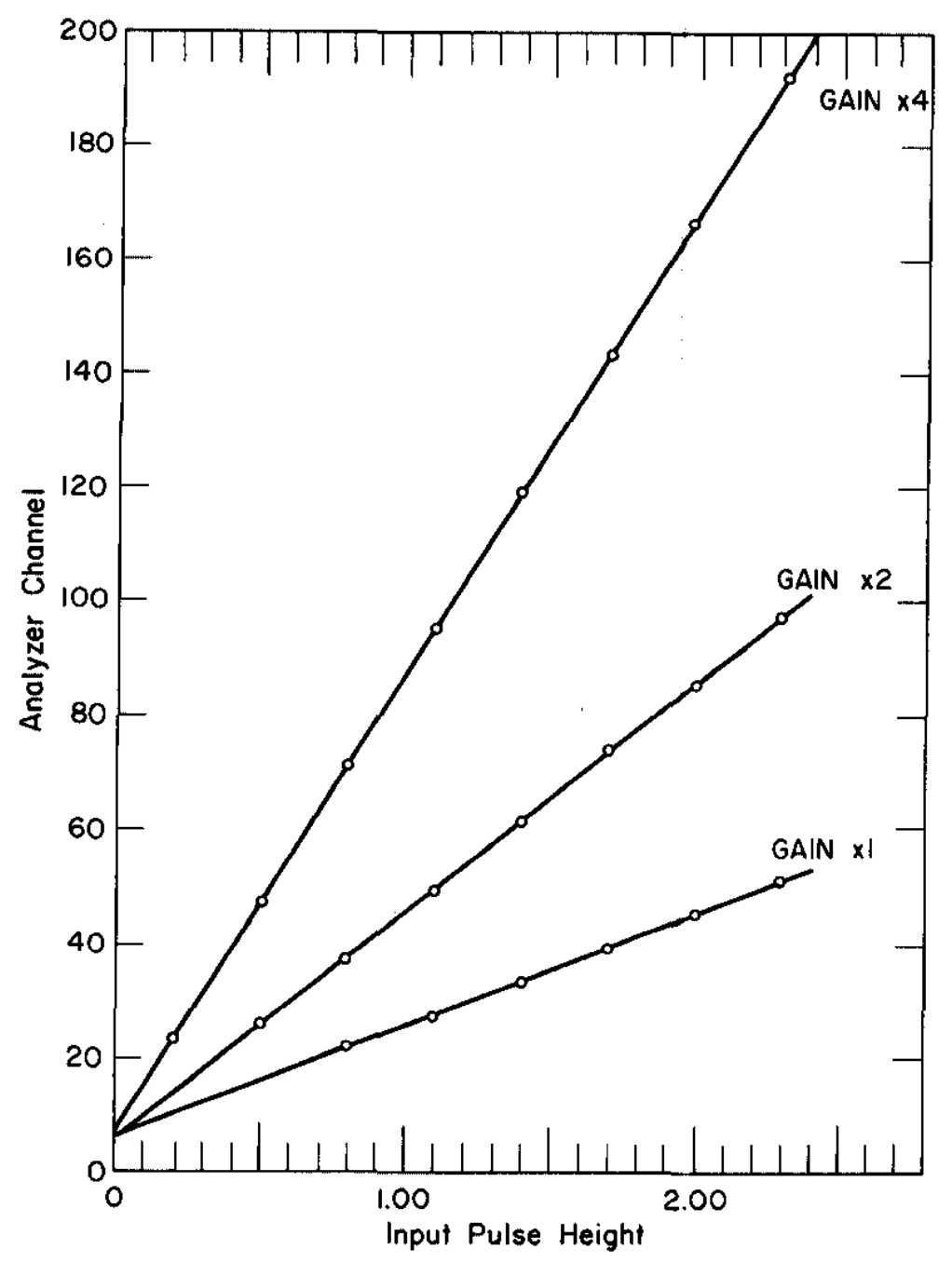

FIG. 11 ELECTRONIC SYSTEM RESPONSE TO PULSE GENERATOR INPUT 
the gain control in the $x^{4}$ position. The Iinearity was also checked by exposing the spectrometer to thermalized neutrons and obtaining the summed thermal peak for a given setting of the amplifier gain control. Figure 12 shows how the thermal peak position on the analyzer scale was then changed by changing the amplifier gain. Once the primary callbration of the system was accomplished, it could be changed by known amounts by simply changing the amplifier gain.

The main disadvantage of the ${ }^{3} \mathrm{He}$ spectrometer is its low efficiency. During the calibration of the system with the neutron generator, the efficlency for detecting 2.20-Mev neutrons was found to be about $5 \times 10^{-0}$. The efficlency should vary with neutron energy in much the same way that the ${ }^{3} \mathrm{He}(n, p)$ cross section varies with neutron energy.

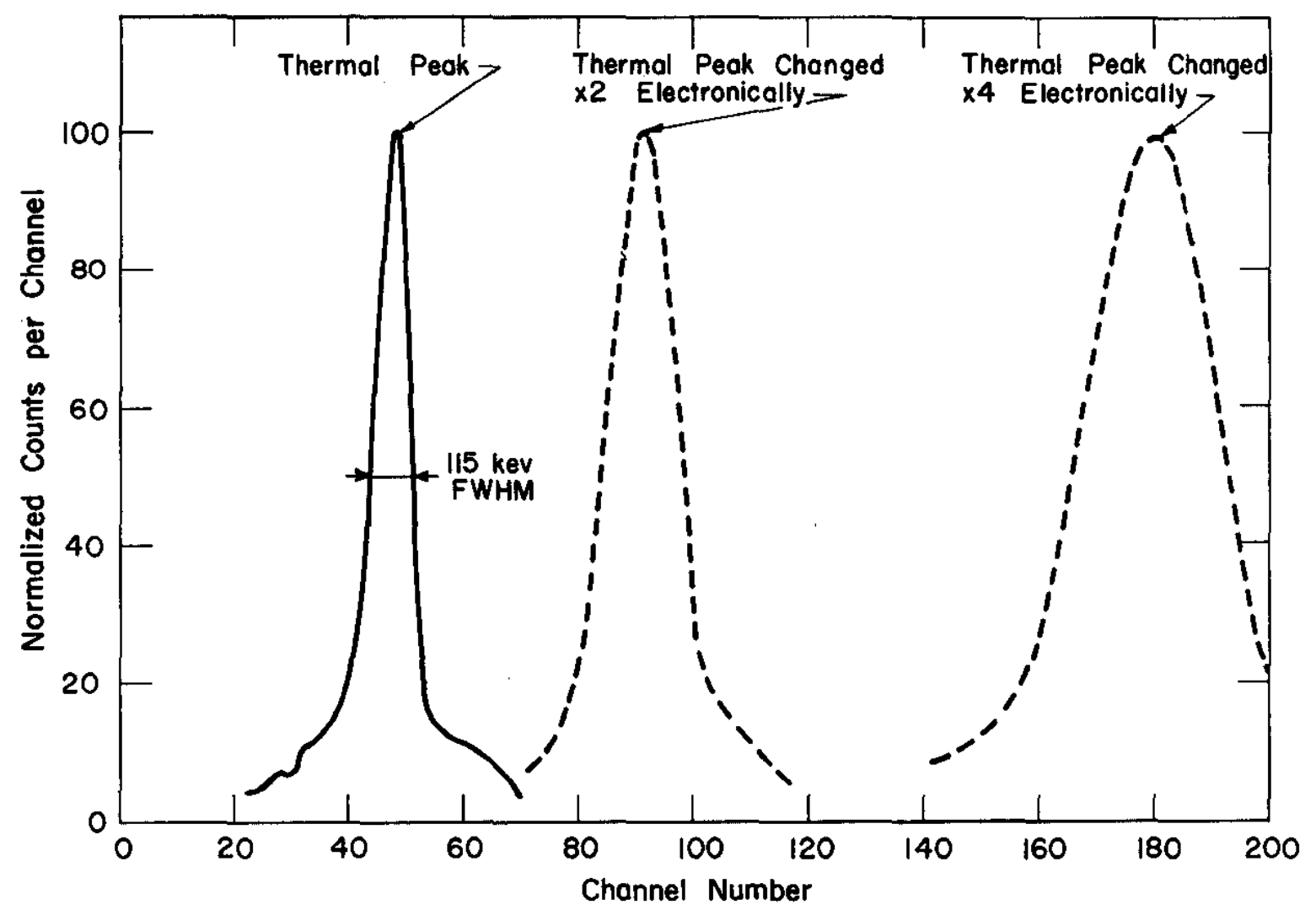

FIG. 12 EFFECT OF ELECTRONIC GAIN ON THERMAL PEAK POSITION 


\section{GAMMA SPECTROMETER}

Figure 13 shows the instruments used to measure the energy spectrum of gamma rays from the spontaneous fission of ${ }^{244} \mathrm{Cm}$. Most of the Instruments used in the ${ }^{3}$ He neutron spectrometer are also used in the gamma spectrometer. In addition to the neutron spectrometer instruments a scintillation detector is used to detect samma rays. Pulses from the scintillation detector are fed through a conventional preamplifier and amplifier to the colncidence analyzer. The colncidence analyzer provides an output signal when the input neutron and gamma signals occur within 180 nanoseconds. The output signal opens the gate of the multichannel analyzer so as to record directly the energy of the gamma ray that participated in the coincidence.

The spectrometer was calibrated by bypassing the coincidence analyzer and determining the photopeaks of ${ }^{137} \mathrm{Cs}(0.662 \mathrm{Mev}),{ }^{60} \mathrm{Co}$ ( 1.173 and $1.333 \mathrm{Mev}$ ), and the composite photopeak of ${ }^{231} \mathrm{~Pa}(0.313 \mathrm{MeV})$.

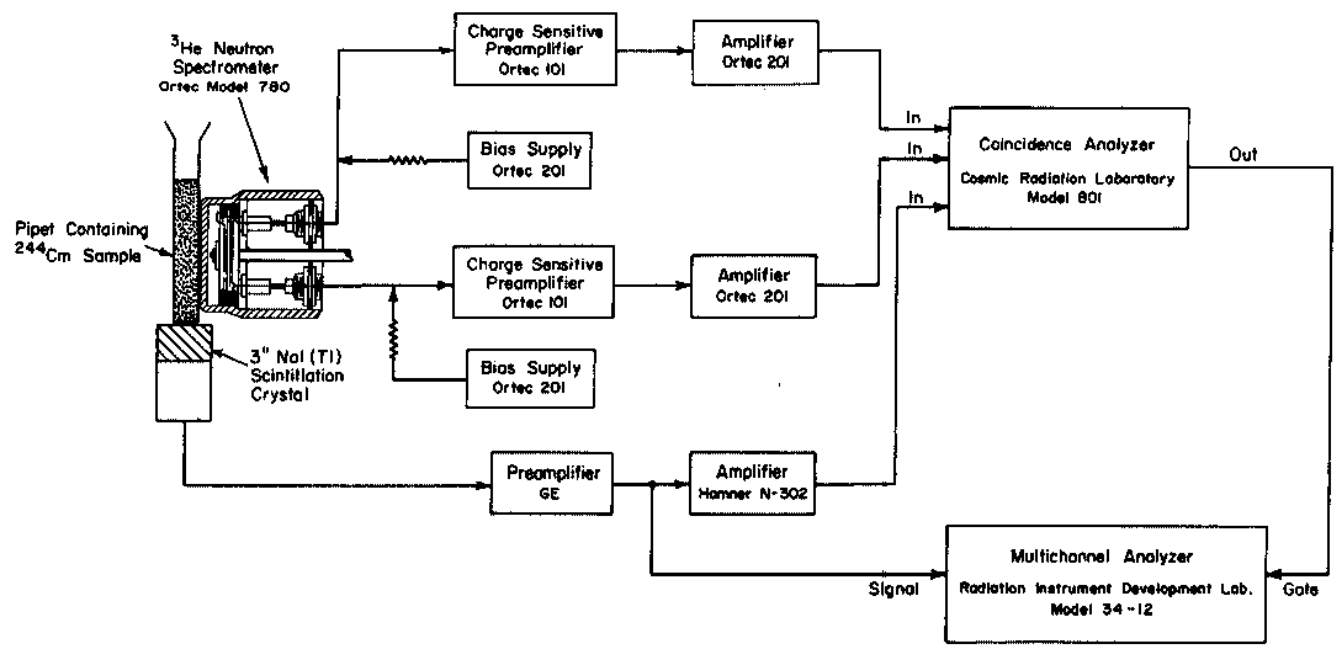

FIG. 13 INSTRUMENTS USED TO MEASURE GAMMA SPECTRA 


\section{REFERENCES}

1. H. J. Groh, R. T. Huntoon, C. S. Schlea, J. A. Smith, and F. H. Springer. ${ }^{1244} \mathrm{Cm}$ Production and Separation-Status of the Pilot Froduction Program at Savannah River." Nucl. Appl. 1 , 327 (1965).

2. T. R. Herold, H. P. Holcomb, R. C. Milham, R. F. Overman, C. S. Schlea, and D. H. Stoddard. Radiation Properties of $244 \mathrm{Cm}$ Produced for Isotopic Power Generators. USAEC Report DP-939, E. I. du Pont de Nemours and Co., Savannah River Laboratory, Aiken, S. C. (1964).

3. H. P. Holcomb. Purification of ${ }^{244} \mathrm{Cm}$ and ${ }^{250} \mathrm{Cf}-252 \mathrm{Cf}$ for Radiation Property Measurements. USAEC Report DP-962, E. I. du Pont de Nemours and Co., Savannah River Laboratory, Alken, S. C. (1965).

4. J. H. Coon. "Disintegration of $\mathrm{He}^{3}$ by Fast Neutrons." Phys. Rev. 80, 488 (1950).

5. J. H. Gibbons and R. L. Macklin. "Total Neutron Yields from Light Elements under Proton and Alpha Bombardment." Phys. Rev. 114, 571 (1959).

6. R. Batchelor, R. Aves, and T. H. R. Skyrme. "Helium-3 Filled Proportional Counter for Neutron Spectroscopy." Rev. Sc1. Instr. 26, 1037 (1955).

7. D. H. Hughes, B. A. Magurno, and M. K. Brussel. Neutron Cross Sections. USAEC Report BNL-325, 2nd Ed., Suppl. 1, Brookhaven Nat1onal Laboratory, Upton, N. Y. (1960).

8. A. B. Smith, P. R. Flelds, R. K. Sjoblom, and J. H. Roberts. "Precise Determination of the $\mathrm{U}^{233}$ Fission Neutron Spectrum." Phys. Rev. 114, No. 5, 1351 (1959).

9. L. Cranberg, G. Frye, N. Nereson, and L. Rosen. "Fission Neutron Spectrum of U235." Phys. Rev. 103, No. 3, 662 (1956).

10. N. Nereson. "Fission Neutron Spectrum of Pu"39." Phys. Rev. 88, No. 4, 823 (1952).

11. A. B. Smith, P. R. Fields, and J. H. Roberts. "Spontaneous Fission Neutron Spectrum of $\mathrm{Cf}^{252} . "$ Phys. Rev. 108, No. 2, 411 (1957). 
12. H. R. Bowman, S. G. Thompson, and J. O. Rasmussen. "Gamma-Ray Spectra from Spontaneous Fission of ${ }^{252} \mathrm{C} f$. Phys. Rev. Letters 12, No. 8, 195 (1964).

13. V. Weisskopf. "Statistics and Nuclear Reactions." Phys. Rev. $\underline{\text { 22, }}$ $295(1937)$.

14. Ya. Frenkel. "The Solid-Body Model of Heavy Nucle1." Physik. Z. Sowjetunion 9, 533-6 (1936) (In English).

15. J. Terrell. "Fission Neutron Spectra and Nuclear Temperature." Phys. Rev. 113, No. 2, 527 (1959).

16. J. S. Fraser. "The Angular Distribution of Prompt Neutrons Emitted in Fission." Phys. Rev. 88, 536 (1952).

17. F. C. Maienschein, R. W. Peele, W. Zobel, and T. A. Love. "Gamma Rays Assoclated with Fission." Proc.U. N. Intern. Conf. Peaceful Uses Atomic Energy, 2nd, Geneva, 15, 366 (1958).

18. K. G. McKay. "A Germanium Counter." Phys. Rev. 76, 1537 (1949).

19. J. Mayer and B. Gossick. "Use of Au-Ge Broad Area Barrier as Alpha-Particle Spectrometer." Rev. Sc1. Instr. 27, 407 (1956).

20. F. A. Love and R. B. Murray. "The Use of Surface-Barrier Diodes for Fast-Neutron Spectroscopy." IRE Transactions on Nuclear Sclence NS-8, No. 1, 91 (1961).

21. J. J. Baum. The Development of a Fast Neutron Spectrometer Using Silicon Surface Barrier Diodes. USAEC and USAF Report Apex 639, General Electric Co., Nuclear Materials and Propulsion Operation, Cincinnati, Ohio (1961).

22. G. Dearnaley and A. T. G. Ferguson. "Two New Semiconductor Detectors for Fast Neutrons." Nucleonics 20, No. 4, 84 (1962).

23. E. S. Kenney. A Semiconductor Detector Fast Neutron Spectrometer. USAEC Report TID-21202, Pennsylvania State University, Department of Physics (1962).

24. T. A. Steele. An Investigation of a Hellum-3 Solld state Fast Neutron Spectrometer. USAEC Report TID-20418, University of Washington, Department of Radiological Science, Seattle, Wash. (1963). 
25. A. Manning, T. Jeter, H. Schuckler, and W. Slack. The Use of the $\mathrm{He}^{3}$ Spectrometer in Neutron Attenuation Measurements. Ballistic Research Laboratories Report BRL-Memo-1545, Aberdeen Proving Ground, Md. (1964).

26. A. Manning, T. B. Jeter, H. Schuckler, and W. Slack. "He Spectrometer Characteristics and Applications." Nucleonics 23, No. 4, 69 (1965).

27. Solid State Radiations, Inc. Solid State Ionlzation Chamber Neutron Detectors. Final Report. Report AD-289566, Nuclear Defense Laboratories, Army Chemical Center, Maryland (1962).

28. J. D. Seagrave, E. R. Graves, S. J. Hipwood, and C. J. McDole. $D(d, n) \mathrm{He}^{3}$ and $\mathrm{T}(\mathrm{d}, \mathrm{n}) \mathrm{He}^{4}$ Neutron Source Handbook. USAEC Report LAMS-2162, Los Alamos Scientific Laboratory, University of California, Los Alamos, N. M. (1958).

29. E. A. Wollcki, R. Jastrow, and F. Brooks. Calculated Efflciencles of NaI Crystals. Report NRL-4833, Naval Research Laboratory, Washington, D. C. (1956). 